\title{
Materiality, parthood, and possibility
}

\author{
Samuele Iaquinto \& Giuliano Torrengo \\ Penultimate draft. Final version to appear in Erkenntnis
}

Abstract: This paper offers an argument in favour of a Lewisian version of concretism that maintains both the principle of material inheritance (according to which, if all the parts of an object $x$ are material, then $x$ is material) and the materiality-modality link (that is, the principle that, for every $x$, if $x$ is material, then $x$ is possible).

Keywords: Lewis' concretism - material object - parthood - possibility - mereological universalism

I. In many if not all versions of concretism, the notion of being material seems to play an implicit or explicit role in characterising possible worlds as concrete entities. For instance, even though in Lewis' theory the notion of materiality has no clear explicit function, possible worlds are often treated as a mereological sum of material entities. This is not surprising, given the paradigmatic position that the physicalist version of concretism has in The Plurality of Worlds.2. In this paper we will argue that the

\footnotetext{
${ }^{\mathrm{I}}$ See, for instance, Lewis (1986), McDaniel (2004), and Yagisawa (2010). The notion of materiality has no explicit role in Lewis (1986) and Yagisawa (2010). Still, it does not seem to us implausible to read their work as implicitly involving this notion. We will say something more on Lewis' treatment of materiality in the next few lines. By contrast, many explicit references to the notion of materiality can be found in McDaniel (2004). If we understand him right, he takes materiality, as in "material object", to be a primitive notion, or at least he does not offer an explicit definition.

${ }^{2}$ Cf. "Maybe, as I myself think, the world is a big physical object; or maybe some part of it are entelechies or spirits or
} 
notion of materiality can be exploited to secure a clearer grasp of the basic tenets of concretism, or at least of those forms of concretism that are Lewisian in spirit.

Our leading idea is that worlds made up of material parts are the "core" examples of concrete worlds for Lewis. We concentrate on those cases, and suggest a natural extension of the theory to concrete worlds that are only partially material, and possibly also to cases of worlds entirely composed of nonmaterial parts. Entities such as universals and tropes, immaterial entelechies and purely mental events are not very natural candidates for concreta. Still, concretists should not (and indeed do not) in principle rule out those entities as denizens of concrete possible worlds. But then the notion of concreteness seems inevitable to play a double role in the concretist picture: on the one hand it characterises the nature of some, but possibly not all, of the parts of possible worlds, on the other hand it applies to any world qua whole. Lewis painfully went through this "instability" by investigating four ways in which the concrete vs abstract distinction can be understood. We think that decoupling the two roles, and giving to materiality the role of the paradigmatic case of concreteness, can help secure the grasp of the whole concretist conception.

Although we take the notion of materiality as a primitive, which we exploit to clarify the behaviour of parthood and possibility in a concretist framework, we will informally gloss it in terms of spatiotemporal location. More precisely, we take the following extensional constraint to hold: an entity $x$ is material if and only if all of $x$ 's proper parts have a spatiotemporal location. Notice that being material does not entail being interconnected, namely having all the parts connected. Archipelagoes and bikinis, for instance, are material entities even if composed of disconnected parts. Besides, there may be entities that are only temporally and not spatially located - mental or spiritual entities for instance. auras or deities or other things unknown to physics.” (Lewis 1986: I) 
Those won't count as material, and although a concretist may eventually accept them in her inventory of what exists, we maintain that they do not have to play a pivotal role in the conceptual foundation of the concretist picture of reality.

II. A methodological desideratum for any theory $T$ is to tell something about how the primitive notions of $T$ behave with respect to at least some of the other notions at play in $T$. Parthood and possibility are two strictly related notions in Lewis' concretism. How do they relate to the notion of materiality? Two principles seem to suggest themselves in Lewis' framework.

The first one can be called principle of Material Inheritance and relates parthood and materiality:

(MI) If some entities are material, then their mereological fusion is material 3

Any spatial parts of the chair on which you are sitting whose fusion is the whole chair are material. Thus, if MI holds, the chair is material as well 4 Similar considerations apply to temporal parts. Any parts of a football match whose fusion is the whole match are material, since their constituents are material entities. Thus, the football match itself is material. MI makes sense also within a four-dimensionalist framework, i.e. within a metaphysics that treats ordinary objects, such as chairs, persons, and cats, as mereological fusions of stages (instantaneous spacetime parts). Arguably, all the stages of Tibbles the

\footnotetext{
${ }^{3}$ In accordance with Quine's (1948) view, here we take terms such as 'object', 'thing', and 'entity' to refer to something existing. More generally, we operate in a Quinean framework, in which the notion of existence is univocal and there are no objects, things or entities that do not exist. See also van Inwagen (2009).

${ }^{4}$ The considerations we make here for MI are possibly even more stringent for a weaker principle than MI, namely (MI*) If all the parts of an object $x$ are material, then $x$ is material (which follows from MI, given very plausible assumptions connecting the notion of mereological sum and that of part). Thanks to the kind suggestion of an anonymous referee, we decided to adopt the stronger principle, since it is not less plausible, and because it allows us to avoid certain awkward assumptions later on (see note 8).
} 
cat are material. If so, each of the stage whose fusion is the whole Tibbles is material. It follows by MI that Tibbles is material. In short, when applied to spatial, temporal, and even spacetime parts, MI expresses a non-trivial, albeit plausible, principle about the relationship between materiality and parthood.

That MI is not trivial is crucial, because it allows us to make interesting explanatory work with respect to the behaviour of the notion of concreteness. MI is not trivial because it connects parthood and materiality in a metaphysically substantive way, by ruling out that an entity having only material parts can be non-material. If we assume that abstract entities are non-material entities, MI rules out the possibility that an abstract entity be composed of material parts. This result is in tension with what Lewis calls the Negative Way of understanding the concrete $v$ s abstract distinction, according to which being abstract means lacking spatiotemporal location. As Lewis points out, unless somehow whole worlds inherit concreteness from the concreteness of their parts (which have spatiotemporal location), according to this way of understanding the distinction it turns out that the concretist's possible worlds aren't concrete after all. As he puts it:

So the right question is: do other worlds and other parts stand in spatiotemporal and causal relation to anything? Parts of worlds do [ ... Whole worlds, however, cannot stand in spatiotemporal and causal relations to anything outside themselves $[\ldots]$. Should we conclude that worlds - including the one we are part of - are abstract wholes made of concrete parts? [ ... That seems unduly literalistic - presumably the Negative Way should be construed charitably, so that wholes can inherit concreteness from their parts (Lewis 1986: 84). 
In this passage Lewis introduces the charitable reading of the Negative Way in what seems a purely ad hoc manner. If the only conceptual insight we have of concreteness is that concrete entities have a spatiotemporal location, then why should something that lacks spatiotemporal location (a possible world) be concrete? Indeed, the idea of the whole inheriting concreteness from its parts here is not just ad hoc, but also in tension with the characterisation of concreteness of the Negative Way. Moreover, it seems clear that Lewis does not rule out that some of the parts of a concrete possible world are not themselves concrete, because maybe some theory of universal is true according to which universals are both part of worlds and abstract, or maybe because there are immaterial entities (e.g., merely spiritual or merely mental ones) $\sqrt{ }$ But then what use is the idea of inheritance of concreteness of the whole from the parts if it cannot be used to explain why possible worlds in general are concrete?

Our idea is that we gain insight into what underlies Lewis' interpretative "charity" here if we think of materiality as the paradigmatic case of concreteness, thus taking materiality to entail concreteness, although the converse does not necessarily hold. We do not loose the material status by "adding" chunks of matter to matter. Thus, we have a very good reason to take a world composed only by material parts to be material, and thus a paradigmatic example of a concrete entity - and a fortiori a concrete entity. But what goes for the paradigmatic case, plausibly goes for the more "fringe" cases. By making such a move, concretists can explain why possible worlds in general should be taken to be concrete. If MI captures an aspect of the concept of materiality qua paradigmatic example of concreteness, then the inheritance of concreteness of a whole world from the concreteness of its parts can be seen as a

${ }^{5}$ After having struggled with the disambiguation of four different ways of interpreting the concrete vs abstract distinction, Lewis concludes that "it seems that indeed I should say that worlds as I take them to be are concrete; and so are many of their parts, but perhaps not all” (1986: 86). 
generalisation of the core case of a world that is entirely material to the more "fringe" cases of non entirely material possible worlds. In other words, the mereological behaviour of the core cases is preserved also in worlds that contain not only material objects, but also non material mental substances and universals, say. And it is preserved regardless of whether all the parts of a concrete possible world are themselves concrete. Therefore, by exploiting MI, a concretist can dispel the uncertainty about the relation between the parts of a possible world and the possible world as a whole that resorting solely to the notion of concreteness seems to bring in. For all those reasons, $\mathrm{MI}$ is not a principle that concretists should abandon light-heartedly.

III. What about the relation between materiality and possibility? It is captured by what we call MaterialityModality link:

(MM) For every $x$, if $x$ is material, then $x$ is possible ${ }^{6}$

MM is a substantive thesis about the relation between materiality and possibility, and it should be no less important to a concretist than MI. Concretist approaches to modality are usually understood as frameworks in which possibility and necessity talk is carried on in a purely extensional manner. Even if not necessarily reductionist in attitude, the extensional background can be exploited to carry out a reduction of modal notions to non-modal ones, at least in so far as the entities we quantify on are not inherently modal. In counterpart theory, for instance, possibility and necessity claims are paraphrased respectively into existentially and universally quantified claims about counterparts - that is

\footnotetext{
${ }^{6}$ Note that MM by itself could be accepted by actualists as well. The reason is simple. The actualist is willing to hold that if $x$ is material, then $x$ is actual. And if $x$ is actual, then a fortiori $x$ is possible. What the actualist disagrees on is the idea that something might be possible without being also actual. However, here we are interested in how a concretist can exploit it to elucidate her framework.
} 
claims about concrete objects and similarity relations between them. It is possible to paraphrase modal talk in analogous ways also without endorsing counterpart theory, and also - more relevantly - without endorsing concretism?

Materiality may have an important role in this, and in particular it might make counterpart theory more philosophically perspicuous than the alternative strategies of extensionalization. If the entities we quantify on in the paraphrase are independently characterised through some non-modal notion (for instance, as being material entities), and we have at our disposal a link between the notion in question and modal notions (such as MM above), a concretist has all what it takes to flesh out a wrought out reductionist account of modality. Thus, MM allows us to have a base for a reductionist approach to modality, even if it does not force us to one. In so far as one motivation for endorsing concretism is to reduce, or in some other sense "tame", modal notions to extensionally more well-behaved ones, MM is an important principle for a concretist.

IV. Although, for the reasons just given, both MI and MM are desirable in a concretist framework, it is possible to show that they are not compatible with the conjunction of two theses that usually go along with the view (and which Lewis explicitly accepts). The first one is Mereological Universalism:

\footnotetext{
${ }^{7}$ Even if, after the development of modal logic, the majority of approaches to modality exploit the machinery of quantification over possible worlds for explicatory (or elucidatory) purposes (notable exceptions being Barwise and Perry 1983), not all of them aim at reducing modal notions to non-modal ones. Approaches such as Forbes (1985), for instance, explicitly assume irreducibly modal properties as grounds of modal truths, and hence count as anti-reductionist. However, certain forms of actualism can be seen as reductionist - at least to a certain extent. Plantinga (1974), for instance, can be seen as an attempt to construe modal notions in terms of individual essences (and set theoretical entities), Adams (198I) as an analogous reductive attempt in terms of world stories, and the proposal of Davies and Humberstone (1980) can be seen as an attempt to reduce metaphysical modality to conceptual connections.
} 
(MU) For every plurality of objects, there exists their mereological fusion $f$.

The second one is a Parthood-Possibility link, based on the idea that "it is possible for something to exist if and only if there is a world in which the whole of it exists” (Lewis 1986: 2II):

(PP) For every $x, x$ is possible if and only if all of $x$ 's parts are part of one possible world.

Let us see why. In the light of MI, the supporter of MU will be bound to hold that, if all the parts of a fusion $f$ are material, then $f$ is material. For instance, the fusion of the legs of the table on which we are writing and its top is a material object. And so is the fusion of our noses and the Eiffel Tower. But what about the fusion of objects belonging to distinct possible worlds? A concretist will read MI as entailing that if some entities existing in distinct worlds are material, then their transworld fusion $t$ is material as well. For instance, the fusion of our noses and a possible talking donkey - let us call it talking nonkey is a material entity $]^{8}$ And thus, given MM, it is a possible entity. However, ex bypothesi, no transworld fusion can be part of only one possible world. Then, in light of PP, talking nonkey is not a possible object. Contradiction. MI, MM, MU and PP are therefore incompatible with each other.

Lewis acknowledges that, in his framework, transworld individuals are not possible objects, although they exist if MU holds. This means that Lewis keeps MU and PP, but rejects at least one of MI and MM. As we read him, Lewis rejects only MM: transworld individuals are impossible material objects. However, he suggests an alternative solution, namely to allow for transworld possible objects by modifying the Parthood-Possibility link as PP' below:

\footnotetext{
${ }^{8}$ Notice that if we had endorsed the weaker principle $\left(\mathrm{MI}^{*}\right)$, given that the vast majority of trans-world entities have other trans-world entities as parts, in order for our example (and any other involving middle size objects) to go through, we should have made the implausible assumption that noses and donkeys are mereological simples.

${ }^{9}$ As he puts it, "transworld individuals are [...] impossible individuals" (1986: 2II, italics in the original).
} 
(PP') For every $x, x$ is possible if and only if all of $x$ 's parts are part of some possible worlds ${ }^{\mathrm{IO}}$

In his words:

To call the trans-world individuals 'impossible' in this sense is not an argument for ignoring them - that comes later. It is only a terminological stipulation. If we thought they should not be ignored, perhaps because we thought that we ourselves were trans-world individuals, it would be appropriate and easy to give 'possible individual' a more inclusive sense. We could say that an individual exists at a world iff, quantifying only over parts of that world, some part of that individual exists - that way, the trans-world individuals would count as possible. (Lewis I986: 2II)

As the quote above shows, Lewis takes the second option - viz. giving "a more inclusive sense" to the notion of possible individual - as conditional on whether we consider transworld individuals as theoretically interesting or not. And in other passages he clearly states that they are not interesting at all. For instance, he takes them to be explanatorily idle with respect to the semantics of modal claims. What allows us to account for the truth-conditions of modal claims is not the fact that such entities exist, but rather the fact that there are appropriate counterpart relations (cf. Lewis 1986: 215-219). But if we are right in maintaining that both $\mathrm{MI}$ and $\mathrm{MM}$ are theoretically crucial for the concretist, whether transworld individuals are theoretically interesting or not is irrelevant. What is relevant is whether the rejection of either MI or MM leads to accept brute, unexplained connections between three central notions of the view - viz. materiality, parthood, and possibility. We argue that it does.

\footnotetext{
${ }^{\text {Io }}$ An analogous reformulation is discussed by Divers (2002, 2014), for different reasons from ours. The followers of Divers' proposal can read our paper as offering a further reason to opt for his treatment.
} 
If $\mathrm{MI}$ is rejected, there is no link between the fact that possible worlds are concrete entities and the fact that their inhabitants in core, paradigmatic cases are material. It is just a further brute fact that those two things go together. If MM is rejected, we are left with a brute correlation between materiality and possibility. This is particularly infelicitous for a reductive approach to modality, in which one of the main theoretical aims is to explain modal facts in terms of similarity facts between entities that inhabit concrete possible worlds. If material entities are paradigmatic concrete entities, then we can generalise to less core cases the consequences of the link between materiality and possibility. If those considerations are on the right track, then the second option suggested by Lewis is indeed the only viable one for the concretist: transworld entities are not only material but also possible.

V. As a final note, we would like to stress that our proposal is not just to endorse PP' over PP. Rather, we think that maintaining both MI and MM is the only way to fully vindicate Lewis' approach to modality, unless the concretist is willing to leave unexplained the crucial points just discussed. Our argument should be taken as aiming to show that MI and MM are two principles that every properly developed Lewisian version of concretism is bound to accept, independently of our opinion on the theoretical interest of transworld fusions.

\section{References}

Adams, R.M. 198I. Actualism and Thisness. Synthese 49: 3-4I.

Barwise, J., Perry, J. 1983. Situations and Attitudes. Cambridge, Mass.: Bradford Books, MIT Press.

Davies, M., Humberstone I.L. 1980. Two Notions of Necessity. Philosophical Studies 38: I-30.

Divers, J. 2002. Possible Worlds. London: Routledge. 
Divers, J. 2014. The Modal Status of the Lewisian Analysis of Modality. Mind I23: 86I-872.

Forbes, G. 1985. The Metaphysics of Modality. Oxford: Oxford University Press.

Lewis, D. 1986. On the Plurality of Worlds. Oxford: Blackwell.

McDaniel, K. 2004. Modal Realism with Overlap. Australasian Journal of Philosophy 82: 137-I52.

Plantinga, A. 1974. The Nature of Necessity. Oxford: Oxford University Press.

Quine, W.V.O. 1948. On What There Is. In W.V.O. Quine. 1953. From a Logical Point of View. New York: Harper, pp. I-19.

van Inwagen, P. 2009. Being, Existence, and Ontological Commitment. In D.J. Chalmers, D. Manley, R. Wasserman (eds.). 2009. Metametaphysics: New Essays on the Foundations of Ontology. Oxford: Oxford University Press, pp. 472-506. Reprinted in P. van Inwagen. 2014. Existence: Essays in Ontology. Cambridge: Cambridge University Press, pp. 50-86.

Yagisawa, T. 2oro. Worlds and Individuals, Possible and Otherwise. Oxford: Oxford University Press. 